\title{
Capturing the Spectrum: Suggested Standards for Conducting Population-Based Traumatic Brain Injury Incidence Studies
}

\author{
Suzanne L. Barker-Collo ${ }^{a}$ Valery L. Feigin ${ }^{b}$ \\ ${ }^{a}$ The University of Auckland, Clinical Training Programme, Department of Psychology, Faculty of Science, \\ Tamaki Campus, and ${ }^{\mathrm{b}}$ National Research Centre for Stroke, Applied Neurosciences and Neurorehabilitation, \\ School of Public Health and Psychology, School of Rehabilitation and Occupation Studies, Faculty of Health and \\ Environmental Sciences, Auckland University of Technology, Auckland, New Zealand
}

Traumatic brain injury (TBI) is a leading cause of disability and death in young adults and a major health problem in childhood [1]. It has a significant impact not only on the individual, but also on their family, extended family, friends and society [2]. One study estimated the annual economic burden of TBI in the USA in 1985 to be approximately USD 4.5 billion in direct expenses for hospital care, extended care and other medical services; an additional USD 20.6 billion in injury-related disability and loss of work; and USD 12.7 billion in lost income from premature death [3]. As significant as these figures are, they may grossly underestimate the economic burden of TBI to family and society because they do not include costs to social services systems, and the value of the time and foregone earnings of family members who care for persons with TBI [4]. Negative consequences for TBI survivors also include an increased mortality risk, longterm physical and/or cognitive disability, and reduced employability [5-7]. Further, TBI results in emotional distress in family members who take on care-giving roles, with resultant increases in use of tranquilisers, alcohol, and counselling services $[8,9]$. Caregivers are described as often being overwhelmed or ill-equipped to provide for the complex needs of individuals with TBI $[10,11]$.

As noted by Bruns and Hauser [6], despite significant differences in study methods which make comparisons difficult (e.g. case ascertainment and inclusion criteria), the general incidence of TBI in developed countries such as the UK, Australia and North America is thought to be approximately 200 people per 100,000 of the population each year [12]. The majority of data published is in regard to hospital admissions or discharges, and often excludes those with milder injuries who are seen only by emergency services, or who do not seek immediate medical attention, those whose TBI is not coded due to being overshadowed by other traumatic injuries (e.g. severe orthopaedic injury) and those with the most severe injuries who die before admission. Thus, the data currently available in the literature does not reflect true incidence. In addition, many of the published studies which purport to impart TBI incidence data reduce comparability by including restricting age limits, limiting case ascertainment to a particular level of injury severity or causal mechanism, and defining inclusion criteria for 'caseness'. The rates reported vary widely, even when similar data sets are accessed. For example, age-adjusted rates from hospital-based studies in the USA range from 544 per 100,000 [13] to a low of 68 per 100,000 [14], with the higher overall rates being produced by utilising the entire Centre for Disease Control TBI database from 13 states, using similar TBI definitions and source data, and including accident and emergency visits, hospitalisations

\section{KARGER}

Fax +4161306 1234 E-Mail karger@karger.ch www.karger.com (c) 2008 S. Karger AG, Basel

0251-5350/09/0321-0001\$26.00/0

Accessible online at:

www.karger.com/ned
Dr. Suzanne Barker-Collo, Department of Psychology, Tamaki Campus

The University of Auckland, Private Bag 92019

Auckland 1142 (New Zealand)

Tel. +6493737599 ext. 88517, Fax +6493738400

E-Mail s.barker-collo@auckland.ac.nz 
Table 1. Suggested standards for a population-based TBI incidence study

\begin{tabular}{|c|c|c|}
\hline Domains & Core criteria & Supplementary criteria \\
\hline $\begin{array}{l}\text { Standard } \\
\text { definitions }\end{array}$ & $\begin{array}{l}\text { World Health Organization criteria for TBI diagnosis [19] } \\
\text { First-ever in a lifetime TBI. } \\
\text { TBI severity classification by GCS [20] - mild: a score of 13-15; } \\
\text { moderate: a score of 9-12; severe: a score of 3-8. }\end{array}$ & $\begin{array}{l}\text { Recurrent TBI. } \\
\text { TBI severity classification by GCS [20] and } \\
\text { duration of PTA as determined from medical } \\
\text { records or relevant PTA scale }[21,22]-\text { mild: } \\
\text { a score of } 13-15 \text { and PTA }<24 \text { h; moderate: } \\
\text { a score of } 9-12 \text { and PTA } 1-6 \text { days; severe: } \\
\text { a score of } 3-8 \text { and PTA } 7+\text { days. }\end{array}$ \\
\hline
\end{tabular}

Standard methods
Complete population-based case ascertainment, based on multiple overlapping sources of information (hospitals, outpatient clinics, general practitioners, death certificates). Prospective study design.

Large well-defined and stable population, allowing at least 100,000 person-years of observation.

Follow-up of patients' vital status for at least 1 month. Reliable method for estimating denominator (not more than 5-years-old census data).

Causes (mechanisms) of TBI recorded.

\section{'Hot pursuit' of cases.}

Direct assessment of under-ascertainment by regular checking of general practitioners' databases and hospital admissions for acute trauma and CT/MRI investigations. Follow-up of patient's functional and vital status up to 1 year or longer after TBI.

\footnotetext{
Standard data Complete calendar years of data.

presentation Men and women presented separately.

Mid-decade age bands (e.g. 25-34 years) used in publications.

$95 \%$ confidence intervals around rates.
}

Unpublished 5-year age bands available for comparison with other studies.

GCS = Glasgow Coma Scale; PTA = post-traumatic amnesia.

and deaths. This is in contrast to the rates presented by Rutland-Brown et al. [14] $(68 / 100,000)$ which appear to be exceptionally low. This low rate could be due to their concentration on accident and emergency visits and hospitalisation with exclusion of deaths, including 12,555 inhospital deaths. Lower rates, for example in Spain [15], may reflect a definition of TBI that was not based upon the ICD code, but rather required loss of consciousness, skull fracture or other objective neurologic findings, making it likely that a number of cases included under ICD criteria would have been excluded (e.g. those with facial lacerations). The literature also appears to disagree in terms of their inclusion/exclusion of deaths, timing of deaths' data collected in relation to TBI (e.g. no deaths' data, all deaths' data, deaths after hospitalization only), and how deaths' information is reported (e.g. annual mortality, proportion of deaths, death ratios, etc.). However, for evidence-based health care planning, prevention and management, it is imperative to have comparable population-based TBI incidence and outcomes studies in various countries and populations [16]. The urgent need for comparable good quality population-based TBI incidence studies has been repeatedly emphasised $[17,18]$.
The methodology of such studies should include standard diagnostic criteria for TBI and ensure complete case ascertainment of all new TBI events (including mild TBI, fatal and non-fatal, hospitalised and non-hospitalised patients) in the population over at least one calendar year and be representative of the population concerned. However, unlike some other common disorders (e.g. stroke, myocardial infarction, multiple sclerosis), no standard methodological criteria exist for carrying out a population-based TBI incidence study. Based on our review of established criteria for population-based studies of other common non-communicable disorders, and for specific sub-classifications of TBI (e.g. paediatric $[17,18]$ ), we would like to suggest standard criteria for populationbased TBI incidence studies to be utilised in future research (table 1). The suggested 'core' criteria are the minimal criteria to ensure methodological validity of a population-based TBI incidence study, while 'supplementary' criteria serve the purpose of advancing the methodological soundness of a study initially based on the 'core' criteria. It is expected that this categorisation of methodological criteria will give more flexibility to researchers in terms of selecting the most appropriate design for their 
own studies, based on their budget and other resources, while providing a standardised methodology that will allow comparability of the studies. As noted by Hans von Holst [23] 'the introduction of standardised injury surveillance systems worldwide is necessary in order to sig- nificantly improve evidence-based practice among physicians dealing with traumatic brain injury' ( $p$ 229). The criteria for population-based TBI incidence studies we propose here may act as the first step in this direction.

\section{References}

1 Ventsel G, Kolk A, Talvik I, Vali M, Vaikmaa M, Talvik T: The incidence of childhood traumatic brain injury in Tartu and Tartu County in Estonia. Neuroepidemiology 2008;30:20-24.

2 New Zealand Guidelines Group: The Diagnosis, Acute Management and Rehabilitation of People after Traumatic Brain Injury. Auckland, Accident Compensation Corporation and District Health Board, 2005.

3 Thurman DJ, Alverson C, Dunn KA, Guerrero J, Sneizek JE: Traumatic brain injury in the United States: a public health perspective. J Head Trauma Rehabil 1999;14:602615.

4 National Institute of Child Health and Human Development: Report of the NIH Consensus Development Conference on the Rehabilitation of Persons with Traumatic Brain Injury. Bethesda, 1998, pp 1-41.

$\checkmark 5$ Masson F, Vecsey J, Salmi LR, Dartigues JF, Erny P, Maurette P: Disability and handicap 5 years after head injury: a population-based study. J Clin Epidemiol 1997;50:595-601.

$\checkmark 6$ Bruns J, Hauser WA: The epidemiology of traumatic brain injury: a review. Epilepsia 2003;44:2-10.

7 Goldstein F, Levin H, Goldman W, Clark A, Altonen T: Cognitive and neurobehavioural function after mild versus moderate brain injury in older adults. J Int Neuropsychol Soc 2001;7:373-383.

$>8$ Kreutzer J, Gervasio A, Camplair P: Patient correlates of caregiver distress and family functioning after traumatic brain injury. Brain Inj 1994;8:211-230.
Livingston MG: Head injury: the relative's response. Brain Inj 1987;1:33-39.

10 Hall KM, Karzmark P, Stevens M, Englander J, O'Hare P, Wright J: Family stressors in traumatic brain injury: a two-year follow-up. Arch Phys Med Rehabil 1994;75:876-884.

11 Gillen R, Tennen H, Affleck G, Steinpreis R: Distress, depressive symptoms, and depressive disorder among caregivers of patients with brain injury. J Head Trauma Rehabil 1998;13:31-43.

12 Torner JC, Schootman M: Epidemiology of Closed Head Injury; in Rizzo M, Tranel D (eds): Head Injury and Postconcussive Syndrome. New York, Churchill Livingstone, 1996.

13 Rutland-Brown W, Langlois JA, Thomas KE, Xi YL: Incidence of traumatic brain injury in the United States, 2003. J Head Trauma Rehabil 2006;21:544-549.

14 Rutland-Brown W, Wallace D, Faul MD, Langlois JA: Traumatic brain injury hospitalizations among American Indians/Alaskan natives. J Head Trauma Rehabil 2005;20 205-215.

15 Vazquez-Barquero A, Vazquez-Barquero JL, Austin O, Pascual J, Gaite L, Herrera S: The epidemiology of head injury in Cantabria. Eur J Epidemiol 1992;8:832-837.

16 Centers for Disease Control and Prevention: Traumatic Brain Injury in the United States. A report to congress. U.S. Department of Health \& Human Services, Centers for Disease Control and Prevention, National Center for Injury Prevention and Control, 1999.
Runyan DK, Berger RP, Barr RG: Defining a ideal system to establish the incidence of inflicted traumatic brain injury: summary of the consensus conference. Am J Prev Med 2008;34:S163-S168.

18 Runyan DK: The challenges of assessing the incidence of inflicted traumatic brain injury: a world perspective. Am J Prev Med 2008;34: S112-S115.

19 Carroll LJ, Cassidy JD, Holm L, et al: Methodological issues and research recommendations for mild traumatic brain injury: the WHO Collaborating Centre Task Force on Mild Traumatic Brain Injury. J Rehabil Med 2004;43(suppl):113-125.

20 Teasdale G, Jennett B: Assessment of coma and impaired consciousness: a practical scale. Lancet 1974;2:81-84.

21 Ponsford J, Willmott C, Rothwell A, Kelly AM, Nelms R, Ng KT: Use of the Westmead PTA scale to monitor recovery of memory after mild head injury (erratum in Brain Inj 2004;18:1065). Brain Inj 2004;18:603-614.

22 Shores E, Marosszeky J, Sandanam J, et al: Preliminary validation of a scale for measuring the duration of post-traumatic amnesia. Med J Aust 1986;144:569-572.

23 von Holst H: Traumatic brain injury; in Feigin VL, Bennett DA (eds): Handbook of Clinical Neuroepidemiology. New York, Nova Science Publishers, 2007, pp 197-232. 